the full extent due to the technical difficulties resulting from the small dimensions of the fetal heart. Secondly, the assessment of the fetal heart function is to enable accurate prediction of the postnatal condition of the newborn, and therefore it must be performed shortly before the expected delivery. Regarding the facts mentioned above, fetal echocardiography performed in the third trimester seems to be an essential element of modern prenatal diagnostics.

This statement was included in the recommendations formulated at the Cardio Prenatal 2017 conference and in the recommendations of the International Prenatal Cardiology Collaboration Group 2017 [1,2]. So far, the largest scientific societies have not emphasised the importance of the assessment of the fetal circulatory system in the third trimester of pregnancy in their recommendations. The International Society of Ultrasound in Obstetrics and Gynaecology (ISUOG) has developed recommendations for prenatal ultrasound examinations in the first and second trimesters of pregnancy, but a similar document on the third trimester of pregnancy has not yet been prepared. According to the ISUOG guidelines, fetal heart assessment is recommended at 18-22 weeks of pregnancy, but these guidelines do not mention the need for performing fetal echocardiography in the third trimester [3]. According to the recommendations published by the American College of Obstetricians and Gynaecologists (ACOG), the main objective of the third-trimester ultrasound examination is to assess the growth and well-being of the fetus and to re-assess its anatomy according to the protocol used in the second trimester of pregnancy. They do not include the assessment of the structure and function of the fetal heart [4]. A similar position is held by the Polish Society of Gynaecologists and Obstetricians. In its recommendations on screening ultrasound diagnosis in normal pregnancy published in 2020 the Society states that the purpose of fetal ultrasound performed in the third trimester of pregnancy is to assess the growth of the fetus and in selected clinical situations to assess its wellbeing [5].

\section{Objective of the article}

Contemporary prenatal cardiology and fetal echocardiography allow us to assess the details of anatomical structure and functional disorders of the fetal heart with an accuracy similar to echocardiographic examinations performed in children and adults [6]. Current recommendations of international scientific societies recommend fetal heart examination only in the $18^{\text {th }}$. $22^{\text {nd }}$ week of pregnancy, and there is a tendency to show its application towards the first trimester of pregnancy. The aim of this article is to demonstrate that the echocardiographic examination of the fetal heart in the third trimester of pregnancy, especially near terms, for functional assessment, is an important and necessary element of prenatal diagnosis.

\section{Pathophysiology of fetal heart dysfunction}

Circulatory failure refers to the inability of the fetal cardiovascular system to provide the required tissue and organ perfusion. Fetal circulatory failure is manifested by impaired systolic-diastolic function of the myocardium, hypertrophy of the myocardium, cardiomegaly, and in the final stage by fetal hydrops. The Cardio- vascular Profile Score is a commonly used to present in simple way the circulatory system efficiency in the fetus [6-9].

Symptoms of circulatory failure in the fetus, such as fetal hydrops, only become apparent late, after the cardiovascular system has exhausted its ability to adapt to the pathological process. They are preceded by more subtle dysfunctions of the heart and its remodelling, which can be seen in detailed fetal echocardiography [10].

The contractility of the heart is understood as the ability to move the walls of the heart cavities in relation to different axes. We distinguish movements along the long axis running from the base to the apex of the heart, movements along the short axis running perpendicular to the interventricular septum, and rotational movements. Movements along the long axis are due to the work of longitudinal muscle fibres located close to the endocardium, which are the most sensitive to hypoxaemia. Therefore, contractility disorders in this axis appear the earliest. Abnormalities of contractility along the short axis of the heart appear later. This short-axis contractility is determined by the work of circular fibres located in the middle of the myocardium and are more resistant to hypoxaemia [10-13].

The pressure generated by the volume of blood filling the ventricles during late diastole determines its preload. It is primarily dependent on the amount of venous blood return. It may be increased in the case of fetal anaemia or in the recipient twin with TTTS. The heart adapts to the increased preload by widening the lumen of the ventricles [10-13].

Afterload is understood as the blood pressure acting on the walls of the ventricles during contraction. It is increased when the outflow tract from the ventricle is narrowed, for example due to stenosis of the semilunar valve. Afterload also increases when blood pressure is increased in the arterial trunks, for example in the case of intrauterine growth restriction. The heart adapts to the increased afterload through myocardial hypertrophy [10-13].

\section{Methods of fetal heart function evaluation in echocardiographic examination}

Using spectral Doppler, it is possible to calculate stroke volume and cardiac output. However, the value of these parameters begins to decline only with advanced disorders of the circulatory system, after exhausting its ability to adapt [10-13].

Spectral Doppler also allows us to assess the blood flow through the large veins supplying blood to the atria of the heart. The assessment of the flow through the ductus venous has found the widest clinical application. The high pulsatility index in the ductus venosus and the presence of a retrograde "a" wave are the effect of increased pressure in the right atrium, which may indicate impaired right ventricular relaxation and/ or its high preload [6, 10-13].

When assessing the spectrum of blood flow through the atrioventricular valves, the E/A ratio can be measured, which is the quotient of the maximum velocity of blood inflow into the ventricles during atrial relaxation, by its maximum velocity during atrial contraction. A value below the reference range for a given gestational age may indicate a weakening of the diastolic function of the heart $[6,10-13]$. 
The myocardial performance index (Tei index, MPI) is a parameter that evaluates both the systolic and diastolic function of the ventricles. Its value depends on the duration of isovolumetric contraction and relaxation and the ejection time from a given ventricle. The high diagnostic value of this parameter results from the fact that its value begins to deviate from the norm at an early stage of the pathological process affecting the circulatory system of the fetus [6, 10-13].

The M-Mode technique evaluates the ventricular shortening fraction (SF), which expresses the degree of narrowing of the ventricular diameter during systole. The ejection fraction can also be calculated using this technique. However, these parameters show deviations from the norm only in the case of advanced fetal heart dysfunction. More sensitive measures of systolic dysfunction are the parameters MAPSE and TAPSE (mitral/tricuspid annular plane systolic excursion), which assess the movement of the annuli of the mitral and tricuspid valves during ventricular contraction. The value of these parameters depends on the efficiency of the longitudinal muscles of the heart, which react early to hypoxaemia [6, 10-13].

The tissue Doppler technique (TDI) measures the speed of movement of the annuli of the atrioventricular valves during the heart cycle. The assessment of these velocities is an early and sensitive measure of systolic-diastolic dysfunction [10, 11-14].

The speckle tracking technique allows the evaluation of myocardial deformation during systole and diastole (parameters such as "strain" and "strain rate" can be measured). Abnormal deformation of the heart muscle is an early symptom of its dysfunction [10, 11-14].

Methods using 3D and 4D ultrasound (such as spatio temporal image correlation, STIC) make it possible to precisely measure the volume of the ventricles in various phases of the heart cycle, thanks to which the ejection fraction can be reliably determined [10-13].

\section{The rationale and goals of fetal echocardiography in the third trimester in uncomplicated pregnancy}

The increase in knowledge and skills of prenatal diagnosticians observed in recent years, as well as the constantly improving quality of imaging resulting from technological progress, enabled the early diagnoses of congenital heart defects in the fetus. Heart defects can be detected as early as at 11-13 weeks of pregnancy with the use of a vaginal probe, and from the $14^{\text {th }}$ week of pregnancy also with the use of a transabdominal probe. Despite the high sensitivity and specificity of fetal echocardiography in the first trimester, it is advisable to reassess the structure of the fetal heart in the $18^{\text {th }}-22^{\text {nd }}$ week of pregnancy in order to verify the earlier diagnosis. Abnormalities rarely diagnosed in the first trimester, such as small ventricular septal defects, completely abnormal pulmonary venous drainage, or abnormalities of the aortic arch, are much more likely to be visualised in the second trimester [15]. However, there is a group of congenital heart defects that are difficult to detect before the third trimester of pregnancy. There is also a group of disorders of the fetal heart function, which usually do not appear until the third trimester of pregnancy [6]. Moreover, if the fetus is monitored using fetal echocardiography over a period of several weeks, and the last examination is performed shortly before delivery, the condition of the newborn in the first hours and days of extrauterine life can be reliably predicted $[1,2,16]$. On the basis of the analysis of echocardiographic examinations of 107 fetuses, Strzelecka et al. demonstrated, that if the anatomy and function of the fetal heart was evaluated as normal at the $37^{\text {th }}$ week of pregnancy or later, the newborn would be born in good general condition in each case [17]. The most important objectives of fetal echocardiography in the third trimester of uncomplicated pregnancy are listed below and will be discussed in detail later in the text: - Reassessment of the fetal heart structure. It makes it possible to detect defects that may have been unnoticed by the fetal echocardiographer in the first and second trimesters. Examples of such defects are as follows: aortic valve stenosis, coarctation of the aorta, perimembranous or muscular ventricular septal defect, and total anomalous pulmonary venous return [18].

- Detection of cardiovascular abnormalities that very rarely occur before the third trimester (for example: premature constriction of ductus arteriosus or foramen ovale in a fetus with normal heart anatomy, increased resistance in the vascular bed of the fetal lungs) [19].

\section{Coarctation of the aorta}

Coarctation of the aorta is one of the most difficult heart defects to diagnose in the prenatal period. This defect, unless recognised before birth, is often insidious and initially asymptomatic. As a consequence, the seemingly healthy newborn is discharged home and in a short time, after the arterial duct is closed, the peripheral perfusion may be reduced, which may lead to circulatory shock and even death. Therefore, the diagnosis of this defect in the prenatal period is very important. The symptom suggesting aortic coarctation that is easiest to spot in fetal echocardiography is the disproportion of the ventricles and great arteries, where the left ventricle and aorta are smaller compared to the right side of the heart. Hypoplasia of the left ventricle and aorta may worsen during pregnancy; therefore, it is advisable to perform serial echocardiographic examinations of the fetus, at least every 4-6 weeks, also in the third trimester $[6,15,20-22]$. It should be noted that at the end of pregnancy, the disproportion between the right and left side of the heart is often present in normal fetuses; therefore, the sensitivity of diagnosing aortic coarctation using the above-described symptoms is the highest before 28 weeks of pregnancy [21,23]. Słodki et al. described a sensitive and specific parameter that allows the assessment of which fetuses with a disproportion at the level of the ventricles observed in the third trimester actually have coarctation of the aorta. This parameter was the ratio of the main pulmonary artery diameter to the diameter of the ascending aorta, measured in the 3-vessel view. The cut-off value of this quotient above which aortic coarctation should be suspected was 1.6 [24]. Other symptoms, more specific to aortic coarctation, are as follows: aortic isthmus narrowing below 
the reference values for a given gestational age, the presence of a characteristic aortic arch shelf at the isthmus level, and abnormal blood flow through the aortic isthmus (turbulent flow, retrograde flow through the isthmus into the aortic arch) [15, $20,21]$. All the above-mentioned echocardiographic symptoms are most clearly manifested in the third trimester of pregnancy.

\section{Premature constriction of the ductus arteriosus}

Premature constriction of the ductus arteriosus can be diagnosed by echocardiographic examination of the fetal heart. A suggestive symptom is the tortuous course of the ductus arteriosus. An important part of the diagnosis is also the detection of abnormal blood flow through the ductus arteriosus, such as an increased maximum systolic velocity $(>140 \mathrm{~cm} / \mathrm{s})$ and a reduced pulsatility index $(<1.9)$. Significant narrowing of the ductus arteriosus increases right ventricular afterload. Increased afterload leads to dilatation of the lumen and hypertrophy of the walls of the right ventricle, and to disorders of its systolic-diastolic function. Restriction of blood flow through the narrowed ductus arteriosus may also cause volumetric overload of the pulmonary veins and, consequently, lead to permanent changes in their walls resulting in congenital pulmonary hypertension. Tricuspid valve regurgitation is also common [6, 25-28].

The main task of the prenatal cardiologist in the case of a fetus with premature constriction of the ductus arteriosus is the systematic monitoring of the fetal heart function and assessment of the progression of cardiovascular functional changes. Constriction of the ductus arteriosus is initially well tolerated by the fetus and may be reversible. When long-lasting, however, it may ultimately lead to cardiovascular failure and intrauterine fetal death or complications in the newborn (e.g. pulmonary hypertension). Frequently performed echocardiographic examinations make it possible to predict such a situation and prevent it, informing the obstetrician about the necessity to end the pregnancy in the right moment. On the other hand, if premature constriction of the ductus arteriosus is not associated with significant cardiac dysfunction, the prenatal cardiologist can assure the obstetrician for the welfare of the fetus, which in many cases allows the patient to avoid iatrogenic preterm labour and the related complications of prematurity $[6,25-28]$.

During prenatal life, the patency of the ductus arteriosus is maintained primarily by fetal prostaglandins. In the third trimester of pregnancy, the walls of the arterial duct become more susceptible to substances inducing their contraction, such as prostaglandin synthesis inhibitors. These inhibitors can be pharmacological agents taken by the pregnant woman, especially non-steroidal anti-inflammatory drugs. Polyphenols, such as those found in green tea and yerba mate, also have a similar effect. Due to the above-described pathogenesis, premature closure of the ductus arteriosus is a pathology characteristic almost exclusively for the third trimester of pregnancy [6, 25-29].

\section{Increased fetal lung vascular resistance}

Up to now, abnormalities of the fetal lung vascular bed have not been well described in the medical literature. Meanwhile, increased resistance in the pulmonary vessels accompanies many congenital heart defects and may also be present in fetuses with a normal heart anatomy. Such disorders can lead to irreversible pathological changes in the walls of pulmonary arteries and arterioles, which in turn can lead to congenital pulmonary hypertension in the newborn. Respondek-Liberska et al. demonstrated that the increased resistance in the fetal lung vascular bed in the third trimester of pregnancy may be manifested by mild cardiomegaly, myocardial hypertrophy (mainly related to the right ventricle), disproportion of atria, ventricles, and great arteries in favour of the right side and tricuspid valve regurgitation. It is noteworthy that most of these echocardiographic features also occur with aortic coarctation. The $Z$-score of the diameters of the arterial trunks is a differentiating parameter. The diameter of the pulmonary trunk above the normal range is characteristic of pulmonary hypertension, while the diameter of the ascending aorta below the normal range indicates aortic coarctation $[6,30]$. Pulmonary dilatation appears to be an important prognostic factor in fetuses and newborns with congenital heart disease. Romanowicz et al. described a group of 40 patients with heart defects, who died in the neonatal period, and the pathological examination showed the features of pulmonary hypertension. The ratio of the main pulmonary artery diameter to that of the ascending aorta was significantly higher in this group of patients than in the control group of healthy neonates. It was also significantly higher than in the case of newborns with heart disease (HLHS) who survived the first stage of cardiac surgery [30,31]. Murlewska et al. described a group of 11 newborns with heart defects (such as HLHS, dTGA, and coarctation of the aorta), in whom the diameter of the pulmonary trunk assessed in the third trimester of pregnancy was greater than the $95^{\text {th }}$ percentile (equal to or greater than $12 \mathrm{~mm}$ ). Of these patients, $72.7 \%$ (8/11) died before hospital discharge. Autopsy was performed in of 5 the deceased patients; each of them showed signs of pulmonary hypertension [19].

\section{The rationale and goals of fetal echocardiography in the third trimester in complicated pregnancy}

The diagnosis of a heart defect is the main goal of fetal echocardiography, and the examinations performed in the first and second trimester of pregnancy are focused on carrying out this task. However, it should be emphasised that the role of prenatal cardiology does not end with the diagnosis of the defect. Another, equally important task for a prenatal cardiologist is to assess the impact of a heart defect on the cardiovascular system and fetal well-being and to predict the postnatal condition of the newborn. It should also be emphasised that the assessment of the fetal heart function is also very important in the case of fetuses with a normal heart anatomy, but with other abnormalities complicating the course of pregnancy. These may be pathologies related to the fetus itself, such as congenital defects of other organs, fetal growth restriction, intrauterine infection, or complications of a twin pregnancy. Diseases affecting pregnant woman, such as diabetes, preeclampsia, or lupus are also indications for the assessment of fetal heart function. 
The most important goals of fetal echocardiography in the third trimester of complicated pregnancy are listed below and will be discussed in detail later in the text:

- Prediction of the postnatal state of a newborn in the case of heart defects, which may have different clinical presentations in individual cases. In some cases, urgent interventional treatment on the first day of life in the form of Rashkind procedure (e.g. HLHS or d-TGA with restrictive foramen ovale) or urgent cardiac surgery (e.g. heart tumour, cardiac ectopy, total anomalous pulmonary venous return) may be required.

- Monitoring the progression of evolving heart defects. The evolving nature of a heart defect may be associated with the progression from severe defect treated surgically in a planned manner to a severe, urgent defect, requiring surgical treatment in the first 24 hours of life. An example is the progression of HLHS with normal interatrial communication to HLHS with a restrictive foramen ovale [32].

- Evaluation of the fetal heart function in the case of certain fetal pathologies, such as: fetal growth restriction, twin-totwin transfusion syndrome, and congenital abnormalities of other organs.

- Assessment of fetal heart function in the case of disease of the gravida, such as preeclampsia or diabetes (cardiomyopathy needs to be excluded).

- Evaluation of the fetal heart function when deterioration of its well-being is suspected (e.g. abnormal result of cardiotocography, abnormal Doppler examination).

- Monitoring the impact of intrauterine therapy on the functioning of the fetal circulatory system.

- Monitoring the effects on the fetal circulatory system of analgesics and anti-inflammatory drugs administered on a temporary basis (e.g. in the course of renal colic or toothache).

- Monitoring the haemodynamic status of the fetus in a pregnant woman with autoimmune disease diagnosed before or during pregnancy (e.g. systemic lupus erythematosus, Sjogren's syndrome).

- Confirmation of the well-being of the fetus in the third trimester of pregnancy in order to confirm the safety of continuing pregnancy and preventing premature caesarean section and iatrogenic prematurity due to anxiety of the obstetrician or pregnant woman, e.g. in the case of the umbilical cord wrapping the fetus.

\section{Hypoplastic left heart syndrome}

Detection of hypoplastic left heart syndrome (HLHS) in the prenatal period is not difficult. The more demanding challenge is the correct prediction of the haemodynamic state of the newborn. The most important task of a fetal echocardiograph is to recognise the signs of restriction of the foramen ovale in the fetus. In the case of postnatal restriction, blood flow from the left to the right atrium is obstructed, insufficient oxygenated blood reaches the systemic circulation, pressure in the left atrium increases, and passive pulmonary congestion and haemodynamic instability occur. In such a case, the foramen ovale needs to be widened urgently using the Rashkind procedure or speed in cardiac surgery stage 1 Norwood with atrial septum removal is necessary [33-35].

The most precise method of detecting foramen ovale restriction in the fetus is the assessment of the blood flow spectrum in the pulmonary veins using spectral Doppler. In the case of the foramen ovale restriction, due to the increase in pressure in the left atrium, a retrograde blood flow to the pulmonary veins can be observed during atrial contraction. Velocity Time Integral (VTI), which is the integral of the plot of blood flow velocity against time, is measured. If the VTI forward/reverse (VTI f/r) ratio is between 5 and 3 , this indicates a moderate restriction of the foramen ovale, while when it is less than 3 , there is a restriction a significant degree. This method is characterised by a sensitivity close to $100 \%$ and a specificity of $94 \%$ [36]. Jadczak et al. proved that the assessment of the VTI $\mathrm{f} / \mathrm{r}$ parameter of pulmonary vein flow allowed the identification of patients requiring urgent cardiological work-up with high sensitivity and specificity. For the prediction of the newborn's condition, it was also important to consider the time of duration of foramen ovale restriction [37].

\section{Dextro-transposition of the great arteries}

Prenatal detection and diagnosis of the dextro-transposition of the great arteries (d-TGA), although not trivial, nowadays is not a major difficulty for fetal echocardiographers. Predicting the postnatal condition of a newborn with this defect is much more challenging. The haemodynamic stability of the newborn is conditioned by the possibility of mixing of oxygenated and deoxygenated blood, which is possible thanks to the patency of the foramen ovale and the arterial duct. In fetuses with d-TGA, the risk of premature closure of the ductus arteriosus is higher than in the ones with normal heart anatomy, due to higher oxygen saturation of blood flowing through this structure. The predictor of premature closing of the ductus arteriosus is its narrowing and tortuous course. Colour and pulsed Doppler examination shows a reversal blood flow in the ductus arteriosus. The left and right pulmonary arteries are often dilated, and aorto-pulmonary collaterals can also be observed. The risk of foramen ovale restriction is also higher in D-TGA, which is caused by greater blood flow through the pulmonary arteries and, consequently, increased venous return to the left atrium [38]. Prenatal symptom suggesting the possibility of premature closure of the foramen ovale is its valve hyperkinesia, which ballotizes in the lumen of both atria or aneurysms into the lumen of the left atrium. However, reduced mobility of the foramen ovale valve may also be a symptom of its restriction. There is also a widening of the right atrium and right ventricle. Unfortunately, haemodynamic instability is common also in newborns with TGA, who do not have the above-mentioned prenatal symptoms (e.g. when the last echo test was performed 3 weeks before delivery, while haemodynamic changes may not become apparent until the last week of fetal life). Therefore, one should always be ready for the fact that such a patient may require invasive treatment as soon as in the first 24 hours of life $[15,38]$. A new parameter that can help predict haemodynamic instability in a newborn with d-TGA is 
the value of maximum velocity of blood flow in the pulmonary veins. Słodki et al. proved that in the group of fetuses with dTGA, in whom echocardiography was performed not earlier than 3 weeks before delivery, the maximum blood flow velocity in the pulmonary veins greater than or equal to $41 \mathrm{~cm} / \mathrm{s}$ allowed the prediction of the need to perform atrioseptostomy in a newborn on day 1 of postnatal life with high sensitivity and specificity [39].

\section{Fetal growth restriction}

The fetal growth restriction (FGR) is a pathological entity in which the growth of the fetus is deteriorated. Low fetal weight may be a consequence of congenital defects, chromosomal aberrations, or intrauterine infection with pathogens from the TORCH group. Most often, however, FGR occurs as a result of placental dysfunction. FGR cases resulting from placental dysfunction are divided, depending on the time of the onset of fetal growth disorders, into early FGR (onset at 32 weeks of gestation or earlier) and late FGR (onset after 32 weeks of gestation) [40]. FGR cases can also be classified into stages (from I lightest to IV most severe). The criterion for this classification is the degree of blood flow disturbances in peripheral vessels (such as uterine arteries, umbilical artery, middle cerebral artery, and venous duct), which correlates with the severity of placental dysfunction [41].

However, it should be noted that FGR is also associated with morphological changes in the fetal heart and its dysfunction. The fetal heart must overcome the increased resistance of the placental vessels, which leads to its pressure overload (increased afterload). It is postulated that cardiac volume overload (increased preload) may also occur. Moreover, due to the placenta's dysfunction, the fetal heart is not adequately supplied with oxygen and nutrients. The above-described unfavourable haemodynamic and metabolic conditions result in cardiac dysfunction and its pathological remodelling (heart remodelling) [42]. It has been proven that remodelling affects not only the heart, but also the aortic wall. The changes in the circulatory system are (at least to some extent) permanent, and their consequence may be arterial hypertension in the newborn, as well as an increased risk of cardiovascular diseases in adulthood [43].

Placental dysfunction may also be the cause of another disease entity: preeclampsia. It may be associated with intrauterine growth restriction or normal fetal growth. Due to a similar pathogenesis, the effect of preeclampsia on the circulatory system is similar to that in the case of FGR [44].

Fetal echocardiography allows for the diagnosis of functional disorders and pathological remodelling of the heart, thus identifying patients who may be in a worse haemodynamic condition in the neonatal period and, moreover, are at increased cardiovascular risk in adulthood. The determinants of systolic-diastolic dysfunction are an increased value of the myocardial performance index (MPI) and an extended isovolumetric relaxation time (IVRT) [43, 44]. Using the tissue Doppler technique, it is possible to demonstrate a decrease in the maximum value of the systolic and diastolic velocity of the annuli of the atrioventricular valves. This parameter is an indicator of the weakening of the contractile function of the longitudinal fibres of the heart $[45,46]$. Crispi et al., using the speckle tracking technique, demonstrated that more than half of fetuses with FGR present abnormal myocardial deformation during the heart cycle. This abnormal deformation presented as additional shortening of the interventricular septum in its basal part during the isovolumetric phase of diastole. Newborns with this finding detected in utero were characterised by higher mortality and higher incidence of arterial hypertension [45].

In fetuses with FGR, heart remodelling occurs due to increased afterload. The transverse dimension of the heart measured at the level of the atrioventricular valves increases and the organ becomes more spherical in shape. The severity of cardiac remodelling can be measured using the sphericity index. This parameter can be calculated separately for each chamber or for the whole heart. It is the quotient of the longitudinal dimension of a given ventricle (from the atrio-ventricular valve to the apex) to its transverse dimension (measured at the level of the annuli of the atrioventricular valves).

In some cases, myocardial hypertrophy also occurs, manifested as a thickening of the free walls of the ventricles and the interventricular septum $[43,44]$.

Cruz-Lemini et al. showed that the most important predictors of arterial hypertension in neonates with FGR are abnormal values of the following parameters: TAPSE, right ventricular sphericity index, IVRT, and features of circulatory centralisation in Doppler examination [43].

In the studies published so far, the above-described changes in the structure and function of the fetal heart have not been correlated with the onset of FGR or the degree of its staging, which may be a subject worth exploring in future studies.

\section{Pregestational diabetes mellitus and gestational diabetes mellitus}

The disorders of glucose metabolism observed in pregnancy can be divided into pregestational diabetes mellitus (PGDM) and gestational diabetes mellitus (GDM). The latter is additionally divided into 2 classes: GDM G1, where dietary treatment is sufficient, and GDM G2, where insulin must be included in the treatment [47]. The frequency of congenital heart defects in children of PGDM patients is 2-5 times higher than in the general population, which results from the adverse effect of hyperglycaemia on the development of the fetal cardiovascular system during organogenesis [48]. In the case of GDM, glycaemic control disorders usually occur after the completion of organogenesis, and therefore the incidence of congenital heart defects is not significantly increased in this group [49].

However, it should be emphasised that poor glycaemic control has a negative effect on the fetal heart also in the absence of congenital heart disease (this applies to both PGDM and GDM). Glucose, the concentration of which in the blood of diabetic patients is increased, passes through the placenta into the bloodstream of the fetus. The fetus' response to the threat of hyperglycaemia is increased insulin production. Hy- 
perinsulinaemia leads to the remodelling of the fetal heart muscle. Myocardial hypertrophy occurs, which can be detected by echocardiography by measuring the thickness of the interventricular septum and free ventricular walls [50]. The pathological process described above applies to PGDM and GDM. Another aspect of remodelling the fetal heart in a diabetic pregnancy is changing its geometry. It takes a more spherical shape. Rizzo et al. demonstrated a reduction in the right ventricular sphericity index in fetuses with GDM compared to the control group. The worse the glycaemic control, the lower the sphericity index. It is worth noting, that fetal Doppler flows were normal in the study group of diabetic pregnancies. This fact proves that, in contrast to heart remodelling occurring in FGR, cardiac remodelling was not a consequence of increased afterload, but it was only due to hyperglycaemia and hyperinsulinaemia [51]. Diabetes leads not only to the remodelling of the heart, but also to its dysfunction. In pregnancies with PGDM, deterioration of the diastolic function of the fetal myocardium was observed. It was expressed as a reduction in the E/A ratio. However, such disorders have not been demonstrated in the GDM pregnancies [52]. Respondek-Liberska et al. demonstrated that functional tricuspid valve regurgitation in the fetus may occur with normal heart anatomy in up to $6.8 \%$ of cases, but it occurs much more often when gravida suffers from diabetes [53].

\section{Conclusions}

Fetal echocardiography in the third trimester of pregnancy seems to be a very important tool in contemporary perinatology, and the indications to perform it are extending. Therefore, we all need to focus to increase the number of specialists who will be able to perform fetal echocardiography to improve perinatology care.

\section{Conflict of interest}

The authors declare no conflict of interest.

\section{REFERENCES}

1. Murlewska J, Słodki M, Axt-Fliender R, et al. Recommendations for prenatal echocardiography: a report from international prenatal cardiology collaboration group. Prenat Cardio 2017; 7: 58-63.

2. Czajkowski K, Helwich E, Preis K, et al. Recommendations "cardio-prenatal 2017" from Poland. Prenat Cardio 2018; 8: 5-13.

3. Bishop KC, Kuller JA, Boyd BK, Rhee EH, Miller S, Barker P. Ultrasound examination of the fetal heart. Obstet Gynecol Surv 2017; 72: 54-61.

4. Committee on Practice Bulletins - Obstetrics and the American Institute of Ultrasound in Medicine. Practice bulletin no. 175: Ultrasound in pregnancy. Obstet Gynecol 2016; 128: e241-56.

5. Borowski D, Pietryga M, Basta P, et al. Rekomendacje Sekcji Ultrasonografii Polskiego Towarzystwa Ginekologów i Położników w zakresie przesiewowej diagnostyki ultrasonograficznej w ciąży o przebiegu prawidłowym - 2020 rok. Ginekologia i Perinatologia Praktyczna 2020; 5: 63-75.

6. Respondek-Liberska M. Prenatal Diagnosis Ultrasound and ECHO. [Diagnostyka prenatalna USG/ECHO. Zmiany czynnościowe w układzie krążenia płodu]. PZWL Wydawnictwo Lekarskie, Warszawa 2019.

7. Huhta JC. Guidelines for the evaluation of heart failure in the fetus with or without hydrops. Pediatr Cardiol 2004; 25: 274-286.
8. Sylwestrzak O, Respondek-Liberska M. Echocardiographic methods of fetal heart size assessmentheart to chest area ratio and transversal heart diameter. Prenat Cardio 2018; 8: 20-23.

9. Degenhardt J, Wolter A, Enzensberger C, et al. Myocardial function of hydropic fetuses at the time of diagnosis. Prenat Cardio 2019; 9: 12-16.

10. Crispi F, Gratacós E. Fetal cardiac function: technical considerations and potential research and clinical applications. Fetal Diagn Ther 2012; 32: 47-64.

11. Godfrey ME, Messing B, Cohen SM, Valsky DV, Yagel S. Functional assessment of the fetal heart: a review. Ultrasound Obstet Gynecol 2012; 39: 131-144.

12. Rocha LA, Rolo LC, Araujo Júnior E. How to perform a functional assessment of the fetal heart: a pictorial review. Ultrasonography 2019; 38 : 365-373.

13. Crispi F, Valenzuela-Alcaraz B, Cruz-Lemini M, Gratacós E. Ultrasound assessment of fetal cardiac function. Australas J Ultrasound Med 2013; 16: 158-167.

14. Graupner O, Enzensberger C, Wieg L, et al. Segmental myocardial displacement and tissue velocity analysis of the right ventricle in hypoplastic left heart syndrome fetuses and controls using color tissue Doppler imaging (C-TDI). Prenat Cardio 2017; 7: 12-18.

15. Rogers L, Li J, Liu L, Balluz R, Rychik J, Ge S. Advances in fetal echocardiography: early imaging, three/four dimensional imaging, and role of fetal echocardiography in guiding early postnatal management of congenital heart disease. Echocardiography 2013; 30: 428-438.

16. Strzelecka I, Płużańska J, Węgrzynowski J, Moszura T, Słodki M, Respondek-Liberska M. Routine third trimester fetal cardiac evaluation: time for consideration. Prenat Cardio 2015; 5: 18-23.

17. Strzelecka I, Michalska E, Zych-Krekora K, Respondek-Liberska M. Follow-up on 107 fetuses with normal US + Echo after 37th week of gestation. Prenat Cardio 2017; 7: 26-30.

18. Respondek-Liberska M, Sokołowski Ł, Słodki M, et al. Prenatal diagnosis of TAPVC on Monday, delivery of Tuesday and cardiac surgery at Wednesday-a model of perinatal care in 3rd trimester in case of fetal/neonatal critical heart defect in tertiary center. Prenat Cardio 2016; 6: 37-42.

19. Murlewska J, Sylwestrzak O, Respondek-Liberska M. Unfavorable postnatal outcome with significant dilation of the fetal main pulmonary artery near term. Birth Defects Res 2020; 10.1002/bdr2.1828.

20. Kailin JA, Santos AB, Yilmaz Furtun B, Sexson Tejtel SK, Lantin-Hermoso R. Isolated coarctation of the aorta in the fetus: a diagnostic challenge. Echocardiography 2017; 34: 1768-1775.

21. Gómez-Montes E, Herraiz I, Mendoza A, Escribano D, Galindo A. Prediction of coarctation of the aorta in the second half of pregnancy. Ultrasound Obstet Gynecol 2013; 41: 298-305.

22. Mărginean C, Mărginean CO, Muntean I, Togănel R, Voidăzan S, Gozar L. The role of ventricular disproportion, aortic, and ductal isthmus ultrasound measurements for the diagnosis of fetal aortic coarctation, in the third trimester of pregnancy. Med Ultrason 2015; 17: 475-481.

23. Durand I, Deverriere G, Thill C, et al. Prenatal detection of coarctation of the aorta in a non-selected population: a prospective analysis of 10 years of experience. Pediatr Cardiol 2015; 36: 1248-1254.

24. Slodki M, Rychik J, Moszura T, Janiak K, Respondek-Liberska M. Measurement of the great vessels in the mediastinum could help distinguish true from false-positive coarctation of the aorta in the third trimester. J Ultrasound Med 2009; 28: 1313-1317.

25. Genovese F, Marilli I, Benintende G, et al. Diagnosis and management of fetal ductus arteriosus constriction-closure. J Neonatal Perinatal Med 2015; 8: 57-62.

26. Choi EY, Li M, Choi CW, Park KH, Choi JY. A case of progressive ductal constriction in a fetus. Korean Circ J 2013; 43: 774-781.

27. Weichert J, Hartge DR, Axt-Fliedner R. The fetal ductus arteriosus and its abnormalities - a review. Congenit Heart Dis 2010; 5: 398-408. 
28. Soroka M, Słodki M, Bartoszewicz L, Krukiewicz-Ruta I, Żurawik T, Dobrzańska A. Premature closure of the ductus arteriosus-case presentation. Prenat Cardio 2013; 3: 28-33.

29. Zielinsky P. Constriction of fetal ductus arteriosus and maternal intake of polyphenol-rich foods. Prenat Cardio 2014; 4: 6-18.

30. Respondek-Liberska M, Murlewska J, Wojtowicz-Marzec M, et al. Prenatal echocardiographic findings in newborns with persistent pulmonary hypertension. Ultrasound Obstet Gynecol 2019; 54 (suppl. 1): 307-308.

31. Romanowicz H, Czichos E, Zych-Krekora K, Krekora M, Słodki M, Respondek-Liberska M. Retrospective analysis of prenatal echcardiography findings in cases of congenital heart defects: comparison with postnatal pulmonary hypertension revealed by lungs histopathology (2010-2015). Prenat Cardio 2015; 5: 12-18.

32. Strzelecka I, Moll J, Kornacka K, Zieliński A, Respondek-Liberska M. Does evolving fetal heart defects pose a separate clinical problem? Prenat Cardio $2013 ; 3: 9-14$

33. Pigula FA, Vida V, del Nido P, Bacha E. Contemporary results and current strategies in the management of hypoplastic left heart syndrome. Semin Thorac Cardiovasc Surg 2007; 19: 238-244.

34. Słodki M, Respondek-Liberska M. Hypoplastic left heart syndrome at the tertiary fetal cardiac center: as planned, urgent or severest congenital heart disease? Prenatal classification for obstetricians and neonatologists. Prenat Cardio 2013; 3: 23-27.

35. Sokolowski L, Respondek-Liberska M, Pietryga M, Slodki M. Prenatally diagnosed foramen ovale restriction in fetuses with hypoplastic left heart syndrome may be a predictor of longer hospitalization, but not of a need for an urgent Rashkind procedure. Ginekol Pol 2019; 90: 31-38.

36. Taketazu M, Barrea C, Smallhorn JF, Wilson GJ, Hornberger LK. Intrauterine pulmonary venous flow and restrictive foramen ovale in fetal hypoplastic left heart syndrome. J Am Coll Cardiol 2004; 43: 1902-1907.

37. Jadczak A, Respondek-Liberska M, Sokołowski Ł, et al; International Prenatal Cardiology Collaboration Group. Hypoplastic left heart syndrome with prenatally diagnosed foramen ovale restriction: diagnosis, management and outcome. J Matern Fetal Neonatal Med 2020; 1-8.

38. Talemal L, Donofrio MT. Hemodynamic consequences of a restrictive ductus arteriosus and foramen ovale in fetal transposition of the great arteries. J Neonatal Perinatal Med 2016; 9: 317-320.

39. Słodki M, Axt-Fliedner R, Zych-Krekora K, et al; International Prenatal Cardiology Collaboration Group. New method to predict need for Rashkind procedure in fetuses with dextro-transposition of the great arteries. Ultrasound Obstet Gynecol 2018; 51: 531-536.

40. Figueras F, Gratacos E. Stage-based approach to the management of fetal growth restriction. Prenat Diagn 2014; 34: 655-659.

41. Figueras F, Gratacos E. Update on the diagnosis and classification of fetal growth restriction and proposal of a stage-based management protocol. Fetal Diagn Ther 2014; 36: 86-98.

42. Crispi F, Bijnens B, Figueras F, et al. Fetal growth restriction results in remodeled and less efficient hearts in children. Circulation 2010; 121 : 2427-2436.

43. Cruz-Lemini M, Crispi F, Valenzuela-Alcaraz B, et al. A fetal cardiovascular score to predict infant hypertension and arterial remodeling in intrauterine growth restriction. Am J Obstet Gynecol 2014; 210: 552.e1-552.e22.

44. Youssef L, Miranda J, Paules C, et al. Fetal cardiac remodeling and dysfunction is associated with both preeclampsia and fetal growth restriction. Am J Obstet Gynecol 2020; 222: 79.e1-79.e9.

45. Crispi F, Bijnens B, Sepulveda-Swatson E, et al. Postsystolic shortening by myocardial deformation imaging as a sign of cardiac adaptation to pres- sure overload in fetal growth restriction. Circ Cardiovasc Imaging 2014; 7: 781-787.

46. Comas M, Crispi F, Cruz-Martinez R, Martinez JM, Figueras F, Gratacós E. Usefulness of myocardial tissue Doppler vs conventional echocardiography in the evaluation of cardiac dysfunction in early-onset intrauterine growth restriction. Am J Obstet Gynecol 2010; 203: 45.e1-45.e7.

47. Standards of the Polish Gynecological Society. [Standardy Polskiego Towarzystwa Ginekologicznego postępowania u kobiet z cukrzycą - aktualizacja]. Ginekol Pol 2014; 85: 476-478.

48. Simeone RM, Devine OJ, Marcinkevage JA, et al. Diabetes and congenital heart defects: a systematic review, meta-analysis, and modeling project. Am J Prev Med 2015; 48: 195-204.

49. Bánhidy F, Ács N, Puhó EH, Czeizel AE. Congenital abnormalities in the offspring of pregnant women with type 1, type 2 and gestational diabetes mellitus: a population-based case-control study. Congenit Anom 2010; 50: 115-121.

50. Garg S, Sharma P, Sharma D, Behera V, Durairaj M, Dhall A. Use of fetal echocardiography for characterization of fetal cardiac structure in women with normal pregnancies and gestational diabetes mellitus. J Ultrasound Med 2014; 33: 1365-1369.

51. Rizzo G, Pietrolucci M, Mappa L, Bitsadze V, Khizroeva J, Makatsariya A. Fetal cardiac remodelling in pregnancies complicated by gestational diabetes mellitus: a prospective cohort study. Prenat Cardio 2020: https:// doi.org/10.5114/pcard.2020.94558.

52. Pauliks LB. The effect of pregestational diabetes on fetal heart function. Expert Rev Cardiovasc Ther 2015; 13: 67-74.

53. Respondek ML, Kammermeier M, Ludomirsky A, Weil SR, Huhta JC. The prevalence and clinical significance of fetal tricuspid valve regurgitation with normal heart anatomy. Am J Obstet Gynecol 1994; 171: 1265-1270.

Division of work:

Łukasz Sokołowski (ORCID: 0000-0002-0205-7495): research concept

and design, writing of the article

Maciej Słodki (ORCID: 0000-0002-0160-8013): research concept and

design, critical revision of the article, final approval of the article

Julia Murlewska (ORCID: 0000-0002-8266-4585): critical revision of

the article

Iwona Strzelecka (ORCID: 0000-0003-3469-7064): critical revision of

the article

Paulina Kordjalik (ORCID: 0000-0002-3185-969X): critical revision of

the article

Marek Blitek (ORCID: 0000-0003-1479-3411): critical revision of the

article

Jerzy Węgrzynowski (ORCID: 0000-0002-2213-956X): critical revision

of the article

Mariusz Grzesiak (ORCID: 0000-0002-6900-4347): critical revision of

the article

Michał Krekora (ORCID: 0000-0002-5496-4556): critical revision of

the article

Krzysztof Czajkowski (ORCID: 0000-0001-9106-2837): critical revision

of the article

Krzysztof Preis (ORCID: 0000-0002-8097-3552): critical revision of the article

Maria Respondek-Liberska (ORCID: 0000-0003-0238-2172): research concept and design, critical revision of the article, final approval of the article 